\title{
Um contorno todo aberto - as figuras e o feminino em Maria Gabriela Llansol
}

\author{
Jonas Miguel Pires Samudio e \\ João Luiz Leitão Paravidini*
}

\begin{abstract}
RESUMO
Propomo-nos, por meio da Psicanálise e da Teoria Literária, articular as noções de corpo e de feminino com a proposição llansoliana das figuras, compreendendo que, assim como, para a psicanálise o singular de cada sujeito emerge para além das identidades de uma "unidade do eu", na escrita de Maria Gabriela Llansol cada figura define-se pelo esvaziamento e pela possibilidade de existência para além da fixidez e do fechamento no espelho, como corpos femininos, contornados e abertos.

Palavras-chave: Escrita. Figuras. Psicanálise. Maria Gabriela Llansol.
\end{abstract}

venha o que depois vier ("A eternidade", disseste), só este corpo escreve.

“Apenas o corpo ficará dito", respondi-te.

(LLANSOL, 1998, p. 82).

"Um contorno todo aberto" é a cadeia que intitula, fugaz construção significante, nosso ensaio. E pode ser texto aquilo que o título escreve? Pode, aprendemos com Maria Gabriela Llansol.

Sabemos que a longa tradição acerca do romance, tendo seu início de formação, nos moldes atuais, já no Romantismo, e mais, avançado sobremaneira nos Modernismos, tratou de concentrar nos personagens um de seus títulos mais fortemente desenvolvidos da manualística literária. Curiosamente, situamos o início de tais considerações no Romantismo que, recordamos, surge com a burguesia e com seus anseios de "lançamento" do indivíduo (NUNES, 2005, p. 58). Curiosa, também, é a forma como a tradição literária encara o personagem

* Universidade Federal de Uberlândia. 
como uma personalidade dotada de três níveis de densidade psicológica: a plana, que varia entre o tipo, o estereótipo ou caricatura, e o indivíduo; a plana com pretensão a esférica, e a esférica. (CANDIDO, 1970, p. 62-63). Atravessando o que se diz dos três modelos de personagens, os quais não cabem discutir aqui, o que ressalta é a permanente consideração de que existe uma substância a identificar, como se fosse necessário e sempre possível chegar a um eu restritamente demarcado pelas afirmações que, a respeito de si, são legíveis no texto literário.

Em relação às figuras tais afirmações não são possíveis, e isso afirmamos ao intitular nosso ensaio como "um contorno todo aberto". Nosso trabalho será, pois, o texto desse título, demarcando, a partir da leitura de uma figura llansoliana, o $h a^{1}$ de Inquérito às quatro confidências (2011c), a proximidade entre a proposição de Llansol e as reflexões psicanalíticas a respeito da escrita, naquilo que denominamos, aqui, como a compreensão das figuras do texto de Maria Gabriela Llansol como escritas do corpo feminino: "um contorno todo aberto", como daremos a refletir.

Inicialmente, situamos, a partir de nosso título, o corpo feminino como "um contorno todo aberto", visto falarmos, tão-somente, d'A mulher: o significante da singularidade, do "uma a uma" (LACAN, 2008, p. 17), daquela que não-há, do "genérico absolutamente singular" (CASTELLO BRANCO, 2011, p. 64); nas palavras de Lacan: "Não há $A$ mulher, artigo definido para designar o universal. Não há $A$ mulher pois - já arrisquei o termo, e por que olharia eu para isso duas vezes? - por sua essência ela não é toda" (LACAN, 2008, p. 79 - destaques do autor), sabendo que, sob a bandeira dessas mulheres, qualquer sujeito pode se alinhar. (LACAN, 2008, p. 78). Dessa forma, o "um", aqui, afirma a singularidade, o "uma a uma", do mesmo modo que o "contorno todo aberto" diz do corpo não-todo recoberto pelo simbólico, que mantém-se disponível para "um gozo para além do falo" (LACAN, 2008, p. 80), lendo-se o "aberto" como aquilo que qualifica o "contorno todo": uma película leve, um leve tecido, o espaço de falta inominável e contínua entre o corpo e o vestido, como diz o texto de Llansol:

Sei que não é inomável, ou sê-lo-á tanto como o poder de toque, a relação do corpo ao vestido é que é falha.

(LLANSOL, 2003, p. 56).

1 As figuras que são, a seu modo, termos-noções na Textualidade Llansol (2014), serão grafadas em itálico. 
E sendo corpo e vestido o ponto em que a relação se mostra falha - faltosa, incompleta, a não se dar-, pensamos no elemento de traço, elemento que nos será importante em nossa reflexão, no corpo que a roupa constrói; ademais, pensamos no significado que, no corpo feminino, o vestuário exerce. De fato, nesse "todo aberto", o corpo feminino, a roupa se constitui como um "contorno", como o "traço significante que falta á mulher". (CASTELLO BRANCO, 1989, p. 134). Igualmente, situando nossa reflexão nos vários significantes de que esse corpo faz uso para recobrir-se - haja vista a proliferação substantiva dos trajes femininos, em seus inúmeros acessórios e adereços -, afirmamos o caráter de ostentação da falta, de sua exposição, da exposição da falta que não lugar definido, excêntrico, que circula no corpo d' A que "não existe", espraiando-se como mostra de que a mulher ostenta aquilo que não tem e almeja, num corpo alucinado de completude, alucinado porque a completude, a relação corpo-vestido, corpo-simbólico, é sempre falha. Tal como afirma Lucia Castello Branco: "do nada em que se encontra, a mulher surge como um tudo, uma figura totalizante, sem brechas, sem fraturas, que, tanto na literatura quando no mundo da moda, não passará de uma imagem construída, uma ilusão, uma alucinação”. (BRANCO, 1989, p. 135). Disso advém, novamente demarcamos, o caráter de "todo aberto" do corpo feminino que recebe, da escrita, um "contorno" que, não eliminando as faltas constitutivas desse corpo, o expõe em sua incompletude.

Isso posto, perguntamos, continuando: o há, em Inquérito às quatro confidências, tem "um contorno todo aberto"? Antes dessa, talvez, caberia outra questão: o que entendemos por figura?

Não é possível responder a nenhuma isoladamente. É possível amplificar o pensamento. Comecemos citando Llansol:

À medida que ousei sair da escrita representativa (...) identifiquei progressivamente "nós construtivos" do texto a que chamo figuras e que, na realidade, não são necessariamente pessoas mas módulos, contornos, delineamentos. Uma pessoa que historicamente existiu pode ser uma figura, ao mesmo título que uma frase ("este é o jardim que o pensamento permite"), um animal, ou uma quimera. $\mathrm{O}$ que mais tarde chamei cenas fulgor. Na verdade, os contornos a que me referi envolvem um núcleo cintilante. (LLANSOL, 2011b, p. 121).

As figuras, conforme lemos, são "cenas fulgor", "nós" com os quais o texto se constrói e, acima de tudo, contornos, módulos, delineamentos, restos de frases, de 
imagens ou, como diz Roland Barthes a respeito do "biografema", "algum corpo futuro, prometido à (...) dispersão; uma vida esburacada, em suma” (BARTHES, 2005 , p. XVII). Sendo nós - assim como o real "é um nó que se desata no ponto rigoroso em que uma cena fulgor se enrola, e se levanta" (LLANSOL, 1994, p. 128 - destaques do autor) -, são desenlaçáveis; sendo contornos e delineamentos, são inacabados, envolvem um "núcleo cintilante" a respeito do qual nada se sabe e, mais, que não podem ser vistos por olhar direto, pois:

o que tenho referido raramente é que essas cenas fulgor se verificam sempre na proximidade do que chamo ponto-voraz, e que é simultaneamente a fonte de luz intensa que ilumina a cena fulgor, e o lugar onde ela se anula. Se, por inépcia, a cena é levada demasiado próxima desse ponto, com a intenção de a tornar mais brilhante e viva a cena desaparece, e o olhar cega. Há, assim, que ter o cuidado de desviar o olhar.

(LLANSOL, 1994, p. 140 - destaques da autora).

Desse modo, a figura mantém um espaço de opacidade frente àquele que a olha: intensa, viva, brilhante, que sempre escapa, pois seu centro não está no olho de quem a vê com a leitura. Seu centro é, talvez, aquilo que resta como evidência, o desenho de "uma linha de fulgor" (LLANSOL, 1997, p. 7) - como "um cisco que atravessando um facho de luz revela o facho enquanto tal" (ALMEIDA, 1991, [s/d]) - e a concessão de um outro corpo, tal como afirma Llansol a respeito da figura de Vergílio Ferreira, escritor português falecido e que, em Inquérito às quatro confidências, ganha estatuto figural:

o texto ao fechar o dele quis dar-lhe um corpo de fulgor e de penetração que não se confundisse com o físico, belo ou degradado. Um corpo integralmente feito de linguagem.

Deu-lhes aliados ou comunicantes, sem os quais o vazio provocado da linguagem não consegue ser continuado.

(LLANSOL, 1997, p. 7 - destaques da autora).

Ao tomarmos, no texto de Llansol, o há como figura, sublinhamos seu caráter de corpo de fulgor contornado pela escrita ao qual não é possível dirigir um olhar direto, e cujo núcleo, ponto-voraz, é, talvez, a superfície opaca do texto, o nó em que a cena se levanta, e também a evidência de que esse texto tem um "princípio activo" em devir e simultaneidade. (LLANSOL, 2011b, p. 122-123). Além disso, 
se a figura é identificada com o "vazio provocado", pois a linguagem só existe envolta pelo silêncio que a reverbera em sua vontade de dizer que não se conclui, afirmamos que o há é a continuação daquilo que não se pode dizer, mas apenas contornar, como se escrever fosse desenhar uma linha fulgurante na transparência de uma língua que mostrasse o vazio da não-toda; o que é elucidado, de modo semelhante, por Maurice Blanchot:

o silêncio da linguagem criadora, esse silêncio que nos faz falar, não é apenas uma ausência de palavras, mas uma ausência somente, essa distância que colocamos entre as coisas e nós, e entre nós mesmos, e nas palavras, e que faz com que a linguagem mais plena seja também a mais transparente, a mais nula, como se quisesse deixar fugir infinitamente a própria cavidade que ela encerra, uma espécie de pequena cova do vazio. (BLANCHOT, 2011, p. 81).

Assim, o há deve ser lido e visto de través e a modo de typos figural em Inquérito às quatro confidências, como um corpo montado pelos contornos da escrita, uma estrutura aberta, sobretudo, e posta fora de qualquer pretensa unidade do "eu", visto que esse é algo que falta:

Não vou perguntar: "quem falta?" sou eu que falto, o fragmento por que suspiro, e que está suspenso fora de mim. Eu que queria ser ele, sem poder, como como um resto de frase que se esquece. (LLANSOL, 2011c, p. 21 - destaques da autora).

Contudo, a falta do "eu" também é a falta de um "ele", a falta de "um resto de frase" que cai no esquecimento, mas igualmente é falta de "ela", "o ELA de Gabriela, a parte suspensa que me faz falta" (LLANSOL, 2011c, p. 32 - destaque da autora), o próprio vazio deslumbrado pela linguagem em que o "eu como nome é nada". (LLANSOL, 2011c, p. 41 - destaques da autora). Talvez, por que o nome não seja a consistência de um substantivo, que assinalaria peremptoriamente um referente no mundo; pode ser que, conforme o texto, "de facto, deram-nos um nome, o nome por que nos chamam, mas não é um consistente - é um verbo" (LLANSOL, 2011c, p. 42). Isso assinalamos aqui pelo fato de que há é um nome figural que aponta para fora da identidade, seja essa o "nada", seja o "ser", tal como do "há" fala Emmanuel Lévinas afirmando que ele é "nem nada, nem ser. Emprego, por vezes, a expressão: o terceiro excluído. Não pode dizer-se deste 'há' que persiste, que é 
um acontecimento do ser. Não se pode também dizer que é o nada, ainda que não exista nada”. (LÉVINAS, 2007, p. 34). Ademais, o há pode ser lido como uma cena, o que articula as proposições llansolianas a respeito da figura - a cena fulgor: "na prática, é uma cena infinita - o lugar onde somos figuras" (LLANSOL, 2011c, p. 42) - e a afirmação levinasiana: "ainda que nada existisse, o facto de que 'há' não se poderia negar. Não que haja isto ou aquilo; mas a própria cena do ser estava aberta: há. No vazio absoluto, que se pode imaginar, antes da criação - há" (LÉVINAS, 2007, p. 34). Uma cena aberta contra um "fundo de indeterminação": "o há [y en a], portanto, destaca-se contra o fundo de algo que não tem forma” (LACAN, 2012, p. 125 - destaques no original), diz Lacan a respeito do há, propondo, parece-nos, uma articulação desse com o real, um fundo sem forma em que se desenha a escrita, e cuja informidade insiste em ser contornada.

Convém, de igual modo, destacar que Maria Gabriela Llansol afirma, em entrevista concedida após a publicação de Inquérito às quatro confidências, que:

\begin{abstract}
Digamos, o "há" é a certeza inabalável de que há um núcleo que nunca será destruído e que tem sua existência nele próprio. Eu penso que a energia de certos autores, ou de certos seres humanos, de certos viventes, se funda precisamente nessa existência, nessa força, nessa pujança que lhe assiste sempre com a conviç̧ão de que ela nunca se romperá e nunca atingirá o fim. É uma espécie de bala granítica. (LLANSOL, 2011a, p. 62).
\end{abstract}

"Núcleo", em certo sentido o "núcleo cintilante", e "bala granítica" são os significantes do há de Llansol. Também ele uma cena aberta, não para o ser, não para o nada, mas para o real:

O texto é um afecto meu, procuro ligá-lo a outras pessoas por quem tenho também grande afecto. Talvez lhes sirva. Mas o texto, escrito ou lido, é a cena onde vejo o real,

facto nu no momento em que cruza o belo, e reconheço que avalio a qualidade dos afectos com a mesma medida com que avalio a qualidade dos textos. (LLANSOL, 2011c, p. 98 destaques da autora).

O texto é, assim, na figura do há, a sua cena real em que a nudez dos fatos é atravessada pelo belo, pelo dom poético, na expressão llansoliana. E o Real, conforme Lacan, 
aquele de que se trata no que é chamado de meu pensamento, é sempre um pedaço, um caroço. É, com certeza, um caroço em torno do qual o pensamento divaga, mas seu estigma, o do real como tal consiste em não se ligar a nada. Pelo menos é assim que concebo o real". (2007, p. 119).

Assim, podemos aproximar essa compreensão daquela de Lévinas sobre o "há", e amplificarmos o pensamento sobre este há-real, no texto de Maria Gabriela Llansol que é feito em pedaços, como o há da escrita que não tem começo, nem fim, nem direito, nem avesso:

Um grande crepúsculo inundava a escrita, e todos os factos e conhecimentos se inscreviam num contexto de máxima originalidade; eram derrubados, triturados, nem o direito, nem o avesso existiam. (LLANSOL, 2001, p. 44).

Esta certeza de que a escrita é uma inundação crepuscular aponta para o há como uma busca de palavra para um gozo feminino em que estão abolidas as barreiras e as diferenças - haja vista que crepúsculo é o momento em que não é dia, nem noite, podemos dizer, nem vida, nem morte, mas gozo do entre-lugar - em que a "abertura, assim como o orgasmo feminino, está sempre próximo da desaparição, do desvanecer-se em seu próprio consentimento". (POMMIER, 1991, p. 102). O gozo que porta a condição da ausência, "como se falassem dele numa terceira pessoa ausente". (LLANSOL, 2011c, p. 164). Portanto, o há não demarca qualquer existência, mas, sim, sua condição de "contorno todo aberto" em que o sexo - a abertura extravasada do corpo - é aquilo que se toca: "quando escrevo, sinto as partes na mão (sobretudo, o sexo que lê) e a nostalgia, que, afinal, também é ausência de poder____ desfaz-se e abre-se a cena inconsútil, apesar de ininterrupta, de nossa conversa". (LLANSOL, 2011c, p. 21 - destaques no original). Isso ressalta o fato de que a impossibilidade de se dizer o sexo não é impossibilidade de escrevê-lo na sua impossibilidade, tal como a folha branca e indiferenciada aguarda a marca de um traço desconhecido e inesperado:

nada

se pode dizer 
com

o sexo, mas é com ele que se diz, tal a folha com o lápis (LLANSOL, 2011c, p. 90).

O há é, pois, o próprio corpo que se escreve, fragmentariamente, aberto, bordejando aquilo que é o impronunciável e, em sua feminina falta, é contornado por um além, e "busca sempre a coisa que o signo já não é, como se possível fosse, busca o além da linguagem, o impronunciável, o Real". (CASTELLO BRANCO, 2000, p. 21).

À borda da margem "que a demanda, cujo apelo não pode ser incondicional senão em relação ao Outro, abre sob a forma da possível falha que a necessidade pode aí introduzir, por não haver satisfação universal" (LACAN, 1998, p. 828), o há é essa cena do impronunciável da não-satisfação universal, "como o há é exterior e anterior aos mundos, há e há-sempre é a mesma coisa (...) como houve, há e haverá". (LLANSOL, 2011c, p. 58). Diante da constatação daquilo que não se pode dizer, pode-se deixar que o há gire as afirmações propostas ao redor de si, de forma que, trazendo à memória a afirmação de Lacan de que o real é um caroço, e aproximando dessa o há llansoliano, dizemos, ligando o anterior ao seguinte, o pensamento a se desdobrar: "o há é o caroço desse texto", seu núcleo-duro-semsentido. Ademais, também deixamos o significante - contingente, que "repudia a categoria de eterno e, no entanto, singularmente, (...) é por si mesmo" (LACAN, 2008, p. 46) - deslizar de "o há é o caroço desse texto" para "o há é o caro osso desse texto", com isso ressaltando que o há sustenta a superfície textual. Prosseguindo, dizemos que "o há é a cara medula desse texto", que o vivifica, e também que "o há é o núcleo afetivo desse texto", dizendo que o há, o real, é o que atrai, e seduz o sexo de ler de quem lê para esta relação de legência, a leitura do texto de Llansol, que, pontuamos, à semelhança da relação sexual entre os falantes, é o impossível que se busca pela escrita: "tudo o que é escrito parte do fato de que será para sempre impossível escrever como tal a relação sexual". (LACAN, 2008, p. 40).

Nesse sentido, se é uma "coisa incompreensível termos vivido com um nome próprio" (LLANSOL, 2011c, p. 62), um nome recebido que não recobre a falta de nosso "eu", "ele" ou "ela", e em que a falta de tais palavras é o próprio núcleo de sua atração, afirmamos, com Blanchot:

quando recusa nomear, quando do nome faz uma coisa obscura, insignificante, testemunha de uma obscuridade primordial, o 
que, aqui, desapareceu - o sentido do nome - está realmente destruído, mas em seu lugar surgiu a significação geral, o sentido da insignificância incrustado na palavra como expressão da obscuridade da existência, de modo que, se o sentido preciso dos termos se apagou, agora se afirma a própria possibilidade de significar, o poder vazio de dar um sentido, estranha luz impessoal. (BLANCHOT, 2011, p. 337).

A impessoalidade, o neutro do há, nos diz, assim, da impossibilidade de sair da obscuridade primordial, da própria cena aberta. Por conseguinte, sinalizamos o fato de que "é realmente extraordinário termos nascido numa dada signografia do há em que a nossa biografia se cruza (e tantas vezes se confunde) com a geografia dos mundos". (LLANSOL, 2011c, p. 128). O que aponta para esse cruzamento e confusão como desaparecimento do "eu", do "ele" e do "ela", dizendo que, se a escrita nasce dessa ausência, o há é o modo de causar a vida como uma falha - a do vestido com o corpo, aquela em que "sou no lugar de onde se vocifera que "o universo é uma falha na pureza do Não-Ser"”. (LACAN, 1998, p. 834). Dessa forma, podemos ler o há llansoliano como aquilo que a pulsão de vida desenha como traço - contorno, delineamento - na imensidão da cena - fulgor, cintilante - aberta da pulsão de morte, e o gozo é aquilo que se traça, irritante e contínua e literalmente, como a insistência de um traço que nada diz, e se escreve:

o irritante traço

contínuo.

É apenas uma dobra e um baraço. O texto dobra, efeito de colagem. $\mathrm{O}$ texto suspende o sentido, à espera do dizer exacto. Há frases que só completei anos depois; há frases que, no limiar dos mundos, não devem ser escritas por inteiro; há frases cujo referente de sentido será sempre obscuro. Se eu soubesse escrever um texto sempre limpo, tiraria o traço. (LLANSOL, 2011C, p. 66).

Destaca-se, além da literalidade do traço, sua presença qualificada como “irritante" e "contínuo", tal como o princípio de constância, característico da pulsão que age como "força constante", da qual não é possível fugir (FREUD, 1915/2004, p. 146), pois o "irritante" diz justamente de algo que afeta por sua insistência. Não obstante, o traço llansoliano é uma "dobra", um efeito, e um "baraço”, uma 
corda de enfeixar, açoitar réus ou de enforcá-los, ${ }^{2}$ tal como um efeito de barra, como se o traço marcasse, de fato, seu efeito como a possibilidade da morte por sujeição: gozo de aniquilamento, "num mais além do sexo". (POMMIER, 1991, p. 101). Ademais, pensando nesse traço impossível de ler, visto como impossível de ser acessado em sua representabilidade, ou seja, naquilo que está representando, reportamo-nos ao que Freud afirma, na carta 52 a Fliess, a respeito dos traços $U b$ [Unbewusstsein], traços sem representação possível na consciência e que atestam a presença, na vida psíquica, de elementos que não se ligam a nada, e que se presentificam como traços soltos "sem acesso à consciência" (FREUD, 1996, p. 289), memória inconsciente que permanece como traço, não como significante, como traço mnêmico.

De modo semelhante, o traço, em Llansol, é uma resistência à interpretação, e essa resistência projeta um excesso assinalado pela mão que sustém o lápis, que "sugere-lhe que os envolva com um traço a lápis para assinalar/ o lugar onde cairão por amor". (LLANSOL, 2011c, p. 110). Um traço que assinala a falta, a não-limpeza do texto que torna opaca suas relações referenciais, e o entende como promessa de palavra que não se conclui, tal como fala Gerard Pommier a respeito do gozo feminino:

A palavra presa na mão ecoa por sua ressonância singular e se abre para o todo das outras palavras. Todos os vocabulários são reunidos em alguns sons e se desdobram então. Eles podem evocar essas flores japonesas, que se abrem quando colocadas num pouco de água. A pura percepção, sua infinitude, é roçada ao se falar desse umbral, onde o pai é usualmente invocado para formar frases. Nesse equívoco onde um ausente manifesta sua presença por sua própria falta. (POMMIER, 1991, p. 100).

A partir disso, do ausente manifestado como presente por sua própria falta roçada - poderíamos acrescer, tocada pelo lápis no umbral do indizível -, podemos tracejar o traço como desenhando uma letra muda, que envolve, como auréola, o há: falamos do "h". Sabemos, pois, que na Língua Portuguesa o "h" é letra muda, não representa fonema algum, não se classifica nem como vogal nem como consoante $^{3}$ e só recebe significância fonêmica quando se diz em dígrafos (ch, nh,

2 HOUAISS, "baraço". Disponível em $<$ http://houaiss.uol.com.br/busca?palavra=bara\%E7o $>$. Acesso em 30. nov. 2013.

3 HOUAISS, letra $h$. Disponível em < http://houaiss.uol.com.br/busca?palavra=h>. Acesso em 12. jul. 2013. 
lh). (CEGALLA, 2008, p. 30-31). O "h", consequentemente, é um traço, e talvez, repleto de pulsão erótica, pois, como afirma Llansol a Lucia Castello Branco:

[d]a mesma maneira que eu escrevo um texto único, mais do que um livro, é que faço aquele traço para querer mostrar, de uma maneira muito concreta, que eu sinto mesmo que o traço irrompe, que tudo está ligado a tudo e que sem o tudo anterior não existe o tudo seguinte... A meu ver, aquele traço desloca-me em uma direção em que vou ser tocada fisicamente... Porque o traço é um traço físico. (LLANSOL, 2011a, p. 51).

Assim, se o traço marca a união entre todas as coisas, nos recordamos de que, conforme Freud, "o principal objetivo de Eros [é] unir e atar" (1923/ 2007, p. 54), e, além disso, consideramos o traço do "h" como traço do corpo feminino, "dobra" e "baraço". Letra ausente que se marca por sua presença muda, uma tentativa de que aquilo que não está ligado o seja pela escrita que irrompe como uma linha de fulgor, pulsão "livremente móvel, que pressiona por descarga" (FREUD, 1920/ 2010, p. 198), furo desenhado no real, gozo do que não se inscreve, mas se escreve de modo "irritante" e "contínuo" como possibilidade de silenciar definitivamente. O há, marcado por sua ausência, permanece, como um som-aberto: há, $a$, ah, verbo ter ou existir, interjeição de sussurro-dor-gemido - orgástico, gozante -, primeira letra do alfabeto, artigo feminino, sempre uma abertura do orifício oral, já que, como "um jarro é formado pelo som do jarro, mas eu vejo a palavra jarro que tem o seu bojo no a". (LLANSOL, 2011b, p. 123 - destaque da autora). Contudo, o bojo pode romper-se na distensão, por vezes, se houver A demora para o fechamento da boca e permanecer apenas como fuga de ar; tal movimento concreto, concreto como o traço o é, indica a igual concretude do movimento de saída do ar, pois se a boca não torna a se fechar, a expiração é iminente pela cessação de qualquer inspiração e, nesse sentido, a morte marca sua chegada como gozo de aniquilamento. O há, assim, é a possibilidade de que, escrevendo, se morra, e de que se viva para se "ter um pequeno lugar dentro da morte" (LLANSOL, 1994, p. 51), como afirma o texto de Llansol a respeito do desejo das figuras, pois "o fim do texto é imprevisível estaca subitamente. Fica dito”. (LLANSOL, 2011c, p. 5).

Entre $a$ e há se dá o encontro de simultaneidade e começo: “- Escrevo para girar de $A$ em $H a ́$, rodopiar com as vibrações que sobem e nos elevam até ao lugar em que já não podemos descer, nem evadir-nos - o Há sobre o Há" (LLANSOL, 2011c, p. 45 - destaques da autora); e "vejo as pedras do Egipto caindo dos telhados com o seu nome inscrito. As pedras não são uma metáfora. São todo o 
colorido do $A$ " (LLANSOL, 2011c, p. 134 - destaque da autora). O "a", assim, é um momento de simultaneidade e de começo, um traço ausente do "h" que abre o há para a confrontação da escrita com o silêncio. Como afirma Lacan: "a ruptura, a fenda, o traço de abertura faz surgir a ausência - como o grito não se perfila sobre fundo de silêncio, mas, ao contrário, o faz surgir como silêncio" (LLANSOL, 2011c, 2008, p. 33), do mesmo modo a escrita traceja-se como um gozo na cena aberta do gozo: corpo todo aberto e contornado.

Vemos que a letra que resta é, tão-somente, uma rasura no real por onde escoa o significado como a água sobre o gelo - a imagem é de Lacan, em "Lituraterra" (LACAN, 2009, p. 105-119), traços da escrita que é "amplificar pouco a pouco" (LLANSOL, 2011c, p. 35) sobre a cena infinita do texto. Também recordamos que Lacan designa o objeto como causa de desejo por uma letra, a letra a (LACAN, 2009, p. 113), sublinhando que este objeto só se constitui sobre um resto que falta. Em Llansol, a causa-faltante é a própria escrita, pois "talvez a escrita tenha sido sempre a causa, e não o efeito" (LACAN, 2009, p. 44), e sua cena primitiva:

Sentou-se arranjando as saias, para assistir à produção do texto.

Este texto é um texto que assiste à produção do texto.

Este texto é a cena primitiva do texto.

A mulher não existe, mas é escrita por

(LLANSOL, 2009, p. 23). ${ }^{4}$

E se, conforme lemos, "a mulher não existe, mas é escrita" pelo traço podemos contornar a sua inexistência como uma abertura que há cercada de infinitude:

Há textos reais - trazem uma coroa na sua humildade.

(...)

Há o insondável perfeitamente claro - neste luar libidinal.

Há o sexo de ler

Gostava de lhe ver o rosto

(LLANSOL, 2011c, p. 143 - destaques da autora).

No sexo de ler, ver o rosto. Esse que é a pobreza essencial do outro exposta, a sua nudez como pedido de resposta ao apelo pelo cuidado. (LÉVINAS, 2010, p. 69-70). Ver o rosto do há, essa a aspiração impossível do texto de Llansol, a

4 A frase de Llansol consta no primeiro de seus Diários publicados postumamente, como tendo sido escrita em 14 de fevereiro de 1972. (LLANSOL, 2009). 
aspiração que alcança a abertura da letra "a", um "insondável perfeitamente claro" no "luar libidinal" - talvez outra imagem crepuscular -, em que o traço rompe as barreiras e constitui a experiência como percepção pura do real. Também como o mais próximo da mulher e de sua abertura, como afirma Pommier acerca do "Aberto" de Rilke:

O que é o Aberto? Trata-se desse instante em que, sem que nenhuma barreira constitua obstáculo, os seres e as coisas entram no espaço de uma percepção pura. Nada os opõe entre si, como nada impede que se perceba sua infinita totalidade. Nesse espaço sem barreiras, cada termo por modesto que seja aparece igualmente mostrando à luz de sua unicidade seu esplendor único. (POMMIER, 1991, p. 99).

Portanto, o há, como "contorno todo aberto", é figura da escrita e daquilo que ela desenha: um corpo de mulher, o ponto mais ao longe, no clarão da fenda, na borda do dizível, no último gesto que, tocando o há-do-sexo, é a borda derradeira entre o fulgor e o nada. Como uma pergunta cuja resposta pode ser o gozo do Um, o que é representado como "um saco. Só pode haver Um na imagem de um saco, que é um saco furado. Nada é Um que não saia do saco ou que não entre nele. É essa a fundamentação original do Um". (LACAN, 2012, p. 141). Ou, ainda, que entrega seu sexo como uma imagem sua, contornada e toda aberta e rompida, nossa última imagem:

- Mas o que é um amante?

Ela põe a mão no sexo, e diz-lhe:

- Não é só o faber disto. Isto é a ponta acerada do há. - E leva a mão à cabeça como se ele fosse seu aluno. - Isto - e volta a levar a mão ao sexo aberto que ele olha, mudo de espanto - é auréola e fulgor, mas também força de matar, sobrevivência, nada.

Apesar de estarmos tão próximas, Úrsula nunca teve comigo aquela extrema audácia. Se o faz é porque chegou uma hora. E, num rompante, rasga o seu próprio sexo, sem sofrer. É apenas uma imagem dela.

(LLANSOL, 2011c, p. 109 - destaques da autora). 


\section{Resumen}

Proponemos, por medio de la Psicoanálisis y de la Teoría Literária, articular las nociones de cuerpo y de femenino con la proposición llansoliana de figura, entendiendo que, así como, para la psicoanálisis, el singular de lo sujeto emerge para más allá de las identidades de la "unidad del yo", en la escrita de Maria Gabriela Llansol cada figura se define por lo vacío y por la posibilidad de existencia para más allá de la fijeza, como cuerpos femeninos, contornados y abiertos.

Palabras-clave: Escrita; Figuras; Psicoanálisis; Maria Gabriela Llansol.

Referências:

BARTHES, Roland. Sade, Fourier, Loyola. Tradução de Mário Laranjeira. São Paulo: Martins Fontes, 2005.

BLANCHOT, Maurice. A parte do fogo. Tradução de Ana Maria Scherer. Rio de Janeiro: Rocco, 2011.

CANDIDO, Antonio. A personagem do romance. In: CANDIDO, Antonio et al. A personagem de fiç̧ão. São Paulo: Perspectiva, 1970, p.53-80.

CASTELLO BRANCO, Lucia. Os absolutamente sós: Llansol - A letra - Lacan. Belo Horizonte: Autêntica, 2000.

CAStello BRAnCO, Lucia. A traição de Penélope. São Paulo: Annablume, 2011.

CASTELLO BRANCO, Lucia. Um vulto, uma voz, um véu. In: CASTELLO BRANCO, Lucia; BRANDÃO, Ruth Silviano. A mulher escrita. Rio de Janeiro: Casa-Maria Editorial, 1989, p.133-136.

CEGAllA, Domingos Paschoal. Novíssima gramática da Língua Portuguesa. São Paulo: Editora Nacional, 2008.

FREUD, Sigmund. Carta 52 a Fliess. In: FREUD, Sigmund. Publicações prépsicanalíticas e esboços inéditos (1886-1889). Tradução de Jayme Salomão. Rio de Janeiro; Imago, 1996, p.287-293.

FREUD, Sigmund. (1923). O Eu e o Id. In: FREUD, Sigmund. Escritos sobre a psicologia do Inconsciente, vol. 3. Tradução de Luiz Alberto Hans. Rio de Janeiro: Imago, 2007, p.13-92.

FREUD, Sigmund. (1915). Pulsões e destinos da pulsão. In: FREUD, Sigmund. 
Escritos sobre a psicologia do Inconsciente, vol. 1. Tradução de Luiz Alberto Hans. Rio de Janeiro: Imago, 2004, p.134-173.

FREUD, Sigmund. (1920). Além do princípio do prazer. In: FREUD, Sigmund. Obras completas, vol. 14. Tradução de Paulo César de Souza. São Paulo: Companhia das Letras, 2010, p.161-239.

LACAN, Jacques. O Seminário: Livro 20, Mais ainda. Tradução de M. D. Magno. Rio de Janeiro: Jorge Zahar, 2008.

LACAN, Jacques. Lição sobre "Lituraterra". In: LACAN, Jacques. O seminário: Livro 18, De um discurso que não fosse semblante. Tradução de Vera Ribeiro. Rio de Janeiro: Jorge Zahar, 2009, p.105-119.

LACAN, Jacques. O seminário: Livro 11, Os quatro conceitos fundamentais da psicanálise. Tradução de M. D. Magno. Rio de Janeiro: Jorge Zahar, 2008.

LACAN, Jacques. O seminário: Livro 19, ou pior. Tradução de Vera Ribeiro. Rio de Janeiro: Jorge Zahar, 2012.

LACAN, Jacques. O seminário: Livro 20, mais ainda. Tradução M. D. Magno. Rio de Janeiro: Jorge Zahar, 2008.

LACAN, Jacques. O seminário: Livro 23, O sinthoma. Tradução de Sérgio Laia. Rio de Janeiro: Jorge Zahar, 2007.

LACAN, Jacques. Subversão do sujeito e dialética do desejo. In: LACAN, Jacques. Escritos. Tradução de Vera Ribeiro. Rio de Janeiro: Jorge Zahar, 1998, p. $807-842$.

LÉVINAS, Emmanuel. Ética e infinito. Tradução de João Gama. Lisboa: Edições $70,2007$.

LLANSOL, Maria Gabriela. Ardente texto Joshua. Lisboa: Relógio D’Água, 1998.

LLANSOL, Maria Gabriela. Entrevistas. Belo Horizonte: Autêntica, 2011a.

LLANSOL, Maria Gabriela. Um falcão no punho. Belo Horizonte: Autêntica, $2011 b$.

LLANSOL, Maria Gabriela. Inquérito às quatro confidências. Belo Horizonte: Autêntica, 2011c.

LLANSOL, Maria Gabriela. O jogo da liberdade da alma. Lisboa: Relógio D’Água, 2003.

LLANSOL, Maria Gabriela. Lisboaleipzig 1 - $\mathrm{O}$ encontro inesperado do diverso. 
Lisboa: Rolim, 1994.

LLANSOL, Maria Gabriela. Livro de horas I: Uma data em cada mão. Lisboa: Assírio \& Alvim, 2009.

LLANSOL, Maria Gabriela. A restante vida. Lisboa: Relógio d’Água, 2001.

LLANSOL, Maria Gabriela. O sonho de que temos a linguagem (diário). In: Colóquio/Letras, Lisboa, Fundação Guldanbenkian, 143/144, jan.-jun. 1997, p.518.

MAIA, Elisa Arreguy. Textualidade Llansol. Belo Horizonte: Scriptum, 2014.

NUNES, Benedito. A visão romântica. In: GUINSBURG, J. (Org.). O Romantismo. São Paulo: Perspectiva, 2005, p.51-74.

ALMEIDA, Miguel Calmon du Pin. Se é cara, eu ganho; se é coroa, você perde. Revista Trieb. n. 1. 1991. [s/d]. Disponível em <http://pt.scribd.com/ doc/177120186/trieb1>. Acesso em 30 nov. 2013.

POMMIER, Gerard. A exceção feminina: os impasses do gozo. Tradução de Dulce Duque Estrada. Rio de Janeiro: Jorge Zahar, 1991. 